\title{
Prevalence and Antimicrobial Susceptibility of Escherichia Coli 0157 Isolated From Raw Milk Marketed in Chittagong, Bangladesh
}

\author{
Md. Kauser-Ul Alam ${ }^{1 *}$, Shireen Akther ${ }^{1}$, Nazmul Sarwar ${ }^{1}$, Shamsul Morshed ${ }^{2}$, \\ Goutam Kumar Debnath ${ }^{3}$
}

${ }^{1}$ Department of Food Processing and Engineering, Chittagong Veterinary and Animal Sciences University (CVASU), Chittagong-4225, Bangladesh ${ }^{2}$ Department of Applied Chemistry and Chemical Technology, Chittagong Veterinary and Animal Sciences University, Chittagong-4225, Bangladesh ${ }^{3}$ Department of Dairy and Poultry Sciences, Chittagong Veterinary and Animal Sciences University, Chittagong-4225, Bangladesh A R T I C L E I N F O
Research Article

Received 07 September 2016

Accepted 14 February 2017

Keywords:

Raw milk

E. coli

Microbial analysis

Antibiotics

Antimicrobial susceptibility

${ }^{*}$ Corresponding Author:

E-mail: kause71_sust@yahoo.com \begin{abstract}
A B S T R A C T
Escherichia coli is an emerging public health concern in most countries of the world. It is an important cause of food-borne human disease. The present study assessed the prevalence and determined the antibiotic resistance patterns of E. coli from raw milk marketed in Chittagong, Bangladesh. Of the raw milk marketed in Chittagong 33(18\%) of the 186 raw milk samples of it contains $E$. coli, indicator bacteria for any enteric pathogens. The mean viable count of total bacteria was $4.04 \times 10^{8} \mathrm{cfu} / \mathrm{ml}$ and the mean viable count of $E$. coli in the contaminated raw milk was $1.88 \times 10^{6} \mathrm{cfu} / \mathrm{ml}$. E coli from only six $(18.2 \%)$ of the 33 positive samples yielded colourless colonies across the CTSMAC, suggesting the probable presence of populations belonging to the serotype 0157 and rest of the isolates $27(81.82 \%)$ produced coloured colony on CT-SMAC considering the probable presence of populations belonging to the serotype non-O157. Growth of probable $E$. coli $\mathrm{O} 157$, as evidenced by the colourless colonies on CT-SMAC compared to coloured colonies from other bacteria. Confirmed isolates were further subjected to antimicrobial susceptibility test using the Agar disc diffusion technique. Antibiotics susceptibility profile showed that all the isolates in case of E. coli O157, penicillin $(100 \%)$, tetracycline $(100 \%)$, amoxicillin $(83.33 \%)$ and erythromycin $(83.33 \%)$ were the most resistant whereas ciprofloxacin $(66.67 \%)$, gentamicin $(50.0 \%)$, and streptomycin $(50.0 \%)$ were the most sensitive antibiotics. In case of E.coli non-O157 susceptibility profile showed that chloramphenicol $(40.74 \%)$, erythromycin $(40.74 \%)$ and oxacillin $(37.04 \%)$ were the most resistant whereas ciprofloxacin $(70.37 \%)$, sulphamethoxazole/trimethoprim (S/T) $(59.26 \%)$ and gentamycin $(55.55 \%)$ were the most sensitive antibiotics. The antimicrobial resistance exhibited by E. coli O157and nonO157 strains in this study is an indication of possible antibiotic abuse.
\end{abstract}

\section{Introduction}

Milk is an important source of nutrients to human and animals. Milk meant for human consumption must be free from any pathogenic organisms (Bertu et al., 2010). Microbial contamination in milk may cause milk-borne diseases to humans while others are known to cause milk spoilage. Many milk-borne epidemics of human diseases are spread through milk contamination. Sources of microbial contamination in milk include primary microbial contamination from the infected or sick lactating animal. The secondary causes of microbial contamination occurs along the milk value chain which may include contamination during milking by milkers, milk handlers, unsanitary utensils and/or milking equipment and water supplies used in sanitary activities. Other secondary sources of microbial contamination occur during milk handling, transportation and storage. There is tertiary microbial contamination which occurs mainly due to re-contamination of milk after being processed due to unhygienic conditions and/or poor or

improper handling and storage of milk during consumption (Parekh and Subhash, 2008). The quality of milk is determined by its composition and overall hygiene. However, consumption of contaminated food like milk may lead to food-borne diseases (FBDs). FBDs are caused by the consumption of foods exposed to hazards that may be biological or pathogenic (e.g. viruses, bacteria, parasites), chemical and others physical (Schmidt et al., 2003).

Pathogenic microorganisms commonly isolated from milk and milk products pose a serious threat to human health. Some of these pathogens include E. coli, Staphylococcus aureus, Salmonella spp., Listeria monocytogenes, Brucella abortus, Mycobacterium spp., Campylobacter spp., Leptospira spp., Clostridium spp., Pseudomonas aeruginosa and Proteus spp. (Donkor et al., 2007; Lei et al., 2008). Raw milk is known to be a major vehicle that serves as means of transmission of these milk-borne pathogens to humans. 
Although antibiotics are not recommended for treatment of $E$. coli infections in humans, there is evidence that bacterial isolates are resistant to some antibiotics (Aibinu et al., 2007). The extensive use of antibiotics in both human medicine and for agricultural purposes, particularly, in disease prevention and growth promotion in animal production is a considerable cause of the selection and prevalence of antibiotic resistant E. coli (Schroeder et al., 2002). The development of resistance to antimicrobials is known to occur through stable genetic change heritable from generation to generation through specific mechanisms including mutation, transduction, transformation and or conjugation (Goodman et al., 1990). Because some antibiotics may cause bacterial lysis and liberate the free Shiga toxins in the intestinal tract (Wong et al., 2000), the antimicrobial treatment is contraindicated for human E. coli infections. However, such treatments may be recommended for cystitis and pyelonephritis other than haemorrhagic colitis all caused by $E$. coli (Griffin, 1991). For those limitations of using antimicrobial agents in $E$. coli cases, the generally accepted belief is that the $E$. coli may still be susceptible to most antimicrobials. In addition to their epidemiological importance, the studies of antimicrobials susceptibility of $E$. coli may have more therapeutic significance as recent studies have indicated a possible role of early administration of antimicrobials in preventing the progression of haemolytic uremic syndrome and haemorrhagic colitis both caused by E. coli (Molbak et al., 2002). This study was undertaken to understand the prevalence and antimicrobial resistance pattern in $E$. recovered from raw milk samples.

\section{Materials and Methods}

\section{Selection of Sample Collection Points}

169 Milk samples were collected from the entry points of Chittagong city, Bangladesh: Shikalbaha, Sholoshahar Railway Station, Jalalabad Market, Chittagong City Gate, Halishahar, Chittagong Port, and Chittagong Batali Road. Seventeen samples were directly collected from a dairy farm located in Shikalbaha. The samples were collected between September 2015 and March 2016.

\section{Amount of Collected Sample}

A fluid raw milk sample was collected directly from one of the selected points, mentioned above. The volume of each sample was $250 \mathrm{ml}$.

\section{Sample Collection and Handling}

The samples were directly collected from the bulk sources of incoming fluid raw milk through proper mixing with the help of a plunger and dipper aseptically in a clean sterile bottle. Soon after collection the sample was kept into a cool box for ceasing the growth and activity of acid producing organisms and for shipment to the microbiology laboratory, Chittagong Veterinary and Animal Sciences University (CVASU), where the samples were kept at $0^{\circ} \mathrm{C}$ until investigation.
Selective Plating, Prevalence and Identification of E. coli

For initial screening of $E$. coli from the collected samples, the samples were prepared by serial dilution. $100 \mu \mathrm{l}$ from each milk sample was transferred to $900 \mu \mathrm{l}$ sterile peptone water $(0.1 \%)$ and thoroughly mixed to give 1:10 dilution, the 'first dilution'; serial dilutions were prepared by transferring one $\mathrm{ml}$ from first dilution $\left(10^{-1}\right)$ to $9 \mathrm{ml}$ peptone water, $\left(10^{-2}\right)$ and so on $\left(10^{-3}, 10^{-4}\right)$ as described by Harrigan and McCance (1976). Then each diluted milk sample $(100 \mu \mathrm{l})$ was inoculated onto MacConkey agar medium (Oxoid, Basingstoke, Hampshire, UK), where E. coli produces large pink colour colony after incubation of $24 \mathrm{~h}$ at $37^{\circ} \mathrm{C}$ and the counts were presented as colony forming unites per $\mathrm{ml}$ $(\mathrm{cfu} / \mathrm{ml})$. At the same time diluted milk samples were inoculated onto blood agar medium (Oxoid) for total plate count. The numbers of large pink colonies on MacConkey agar and any bacterial colonies on blood agar from the highest dilution of a milk sample were counted with a colony counter and the total count per $\mathrm{ml}$ of an original milk sample was estimated by multiplying a count with its corresponding dilution factor. To estimate the total viable count of $E$. coli in a sample any large pink colony on MacConkey agar was considered.

Both MacConkey agar medium and blood agar base (Oxoid) were prepared according to the manufacturer instructions. In blood agar base 5\% citrated-bovine blood was added. Five large pink coloured cross-sectional colonies from MacConkey agar medium were homogenized and inoculated onto an Eosin Methylene Blue (EMB) (Oxoid, Basingstoke, Hampshire, UK) agar plate, incubated at $37^{\circ} \mathrm{C}$ for $24 \mathrm{~h}$ to verify whether such population produced colonies with metallic sheen, a diagnostic criterion for E. coli (Dyes Eosin Y and Methylene Blue react with products released by $E$. coli from lactose or sucrose as carbon and energy source, forming metallic green sheen). The isolates from MacConkey produced metallic sheen on EMB were considered as probable E. coli. A portion of a colony displaying characteristic metallic sheen on EMB was inoculated into Trypticase Soya Broth (TSB) (Oxoid), incubated at $37^{\circ} \mathrm{C}$ for $20 \mathrm{~h}$.

\section{Biochemical Tests}

Finally these were tested for standard biochemical tests for E. coli, e.g Catalase test, Indole, Methyl red, Voges- Proskauer test, Nitrate reduction, Urease production, Simmon's citrate agar, and various sugar fermentation tests (add reference) (Table 1). When a broth culture in TSB gave typical reactions was finally deduced as $E$. coli, and then preserved at $-80^{\circ} \mathrm{C}$ with $15 \%$ glycerin.

Phenotypically Determination of O157 and Non-O157 E.coli

Cefixime-Tellurite-Sorbitol MacConkey (CT-SMAC) agar (Oxoid, Basingstoke, Hampshire, UK) added with cefixime tellurite, which is a selected medium for EHEC O157, was initially used in this study to screen any probable presence of $E$. coli. $\mathrm{O} 157$ which is incapable of fermenting sorbitol and thus produces colorless colonies on this medium. CT-SMAC agar was prepared according to the manufacturer's instructions. Briefly, $25.75 \mathrm{~g}$ 
sorbitol MacConkey agar was weighed, mixed with 500 $\mathrm{ml}$ of distilled water and autoclaved. The medium in the flask was then placed in a hot water bath until become cooled to $50^{\circ} \mathrm{C}$ when $2 \mathrm{ml}$ of cefixime tellurite (potassium tellurite $1.25 \mathrm{mg}$ and cefixime $0.05 \mathrm{mg}$ ) was added to it. Cefixime-tellurite (CT) added medium was poured into petridishes at the amount of about $20 \mathrm{ml}$ medium per petridish, and the medium in petridishes are preserved at $+4^{\circ} \mathrm{C}$ before the use, as recommended.

Growth of a probable EHEC O157 colony on a CTSMAC agar plate was presumptively diagnosed if it was slightly transparent, colorless with a weak pale brownish appearance, and with a diameter of $1 \mathrm{~mm}$. Five such crosssectional colonies were picked up and transferred to a 10 $\mathrm{ml}$ test tube containing $5 \mathrm{ml}$ of TSB, incubated at $37^{\circ} \mathrm{C}$ for $6 \mathrm{~h}$ and preserved at $-80^{\circ} \mathrm{C}$ with $15 \%$ glycerin until investigation, for observing antibiotic resistance pattern.

Table 1 Typical biochemical reactions shown by any isolate belonging to $E$. coli

\begin{tabular}{l|c}
\hline \multicolumn{1}{c|}{ Biochemical test } & Reaction \\
\hline Lactose fermentation & $+\mathrm{ve}$ \\
Catalase & $+\mathrm{ve}$ \\
Simmon's Citrate & $-\mathrm{ve}$ \\
Indole Production & $+\mathrm{ve}$ \\
Nitrate Reduction & $+\mathrm{ve}$ \\
Methyl Red & $+\mathrm{ve}$ \\
Voges- Proskauer & $-\mathrm{ve}$ \\
Urease & $-\mathrm{ve}$ \\
\hline Acid from Sugar & \\
\hline (a) Glucose & $+\mathrm{ve}$ \\
(b) Mannitol & $+\mathrm{ve}$ \\
(c) Lactose & $+\mathrm{ve}$ \\
(d) Salicin & $+\mathrm{ve}$ \\
(e) Sucrose & $+\mathrm{ve}$ \\
\hline
\end{tabular}

Antimicrobial Susceptibility Testing

The isolates were screened for antimicrobial susceptibility, using the agar disk diffusion method by Kirby-Bauer, (1966). The following antibiotics (Oxoid) were used: Penicillin (10 units), Gentimicin $(10 \mu \mathrm{g})$, Ciprofloxacin $(5 \mu \mathrm{g})$, Streptomycin $(10 \mu \mathrm{g})$, Amoxycillin $(25 \mu \mathrm{g})$, Tetracycline $(30 \mu \mathrm{g})$, Chloramphenicol $(30 \mu \mathrm{g})$, Oxacillin $(5 \mu \mathrm{g})$, Erythromycin $(5 \mu \mathrm{g})$ and $\mathrm{S} / \mathrm{T}(25 \mu \mathrm{g})$. The isolates were uniformly streaked on Muller-Hinton agar (MHA) (Oxoid) plate and the antibiotic impregnated discs were applied onto the inoculated plates using sterile forceps. The plates were then incubated at $37^{\circ} \mathrm{C}$ for $24 \mathrm{~h}$, after which clear zones of inhibition for each antibiotic were measured using transparent ruler. The results were interpreted using the Clinical and Laboratory Standards Institute (CLSI) criteria (CLSI, 2005).

\section{Results}

Proportion of Milk Samples Positive with E. coli Of the 169 raw market milk samples, 31(18.3\%) were found positive with $E$. coli and out of the 17 samples from a dairy farm $2(11.8 \%)$ yielded $E$. coli characteristic growth of bacterial colonies produced on MacConkey and EMB agar plates.

\section{Prevalence of Bacterial Contamination}

The total viable count of bacteria from the milk samples, regardless from entry points to the city or from a farm, as plated on blood agar plates was minimum $1.7 \times 10^{6} \mathrm{cfu} / \mathrm{ml}$ and maximum $9.70 \times 10^{9} \mathrm{cfu} / \mathrm{ml}$ whereas mean minimum total viable count observed as $8.54 \times 10^{7}$ $\mathrm{cfu} / \mathrm{ml}$ and maximum was $7.37 \times 10^{8} \mathrm{cfu} / \mathrm{ml}$ are shown in Table 2. In total, as mentioned already 33 samples had $E$. coli and its total viable count (based on the counts of large pink colonies on MacConkey agar), was minimum $1.10 \times 10^{4} \mathrm{cfu} / \mathrm{ml}$ and maximum $1.20 \times 10^{7} \mathrm{cfu} / \mathrm{ml}$ ) whereas the mean minimum total viable count recorded as $2.30 \times 10^{5} \mathrm{cfu} / \mathrm{ml}$ and maximum was $1.20 \times 10^{7} \mathrm{cfu} / \mathrm{ml}$ are shown in Table 3.

\section{Presence of probable EHEC O157 and non-O157}

E. coli from only six $(18.2 \%)$ of the 33 positive samples yielded colorless colonies across the CT-SMAC, suggesting the probable presence of populations belonging to the serotype O157. Growth of probable $E$. coli $\mathrm{O} 157$, as evidenced by the colorless colonies on CTSMAC compared to coloured colonies from other bacteria.

\section{Antimicrobial Susceptibility Pattern of E .coli O157}

Table 4 shows the antimicrobial susceptibility patterns of the six E. coli O157, isolated from locally collected raw milk samples, using 10 antibiotics. 4 (66.67\%) were sensitive to ciprofloxacin, $3(50.0 \%)$ of the isolates were sensitive to gentamicin and streptomycin, 2 (33.33\%) were sensitive to trimethoprim, $1(16.67 \%)$ were sensitive to chloramphenicol, amoxicillin and oxacillin and none was sensitive to penicillin, tetracycline and erythromycin. Antibiotic susceptibility profile showed that virtually all the isolates were resistant to one or multiple antibiotics. However, six $(100.0 \%)$ of the six E. coli 0157 isolates were resistant to penicillin and tetracycline, $5(83.33 \%)$ were resistant to amoxicillin and erythromycin, 4 $(66.67 \%)$ were resistant to oxacillin and chloramphenicol, $3(50.0 \%)$ were resistant to S/T, $2(33.33 \%)$ were resistant to streptomycin and none was resistant to ciprofloxacin and gentamicin. Ciprofloxacin, gentamicin, and streptomycin were the most sensitive antibiotics whereas penicillin, tetracycline and erythromycin were the least sensitive.

Antimicrobial Susceptibility Pattern of E .coli Non-O157

Table 5 shows the antimicrobial susceptibility patterns of the $27 \mathrm{E}$. coli non-O157, isolated from locally collected raw milk samples, using 10 antibiotics. 19 (70.37\%), 16 $(59.26 \%), 15(55.55 \%)$ and $12(44.44 \%)$ were sensitive to ciprofloxacin, S/T, gentamycin and amoxicillin, respectively. $10(37.04 \%)$ were sensitive to streptomycin, erythromycin and oxacillin. Ciprofloxacin, S/T, gentamycin and amoxicillin were the most sensitive antibiotics whereas chloramphenicol 8(29.63\%), tetracycline $6(22.22 \%)$ and penicillin $2(7.41 \%)$ were the least sensitive. On the other hand, 11 (40.74\%) for chloramphenicol and erythromycin, $10(37.04 \%)$ oxacillin and $7(25.93 \%)$ for penicillin and streptomycin were the most resistant, whereas $0(0.0 \%)$ for ciprofloxacin and gentamycin, 4 (14.81\%) amoxicillin and 5 (18.52\%) tetracycline were the least resistant. 
Table 2 The mean, maximum and minimum number of bacterial counts on blood agar (any colonies) from the samples investigated in the study

\begin{tabular}{l|ccccc}
\hline \multirow{2}{*}{ Sampling areas } & No. of samples & No. of +ve on & \multicolumn{3}{c}{ TVC in BA (cfu/ml) } \\
\cline { 4 - 6 } & collected & MacConkey agar & Averages & Maximum & Minimum \\
\hline A dairy farm at shikalbaha & 17 & 6 & $7.37 \times 10^{8}$ & $8.8 \times 10^{9}$ & $1.7 \times 10^{6}$ \\
Shikalbaha & 11 & 5 & $8.54 \times 10^{7}$ & $2.72 \times 10^{8}$ & $2.11 \times 10^{6}$ \\
Sholoshahar & 39 & 14 & $7.37 \times 10^{8}$ & $9.70 \times 10^{9}$ & $2.2 \times 10^{6}$ \\
Jalalabad & 20 & 3 & $4.49 \times 10^{8}$ & $1.73 \times 10^{9}$ & $2.88 \times 10^{6}$ \\
City Gate & 19 & 4 & $3.31 \times 10^{8}$ & $1.87 \times 10^{9}$ & $2.7 \times 10^{6}$ \\
Halishahar & 22 & 5 & $3.68 \times 10^{8}$ & $1.54 \times 10^{9}$ & $2.79 \times 10^{6}$ \\
CTG port & 24 & 4 & $2.48 \times 10^{8}$ & $1.59 \times 10^{9}$ & $2.83 \times 10^{6}$ \\
Bataliroad & 34 & 10 & $9.48 \times 10^{7}$ & $1.22 \times 10^{9}$ & $2.47 \times 10^{6}$ \\
Mean & & & $4.04 \times 10^{8}$ & $3.34 \times 10^{9}$ & $2.46 \times 10^{6}$ \\
\hline
\end{tabular}

TVC: Total Viable Count, BA: Blood Agar

Table 3 The mean, maximum and minimum no. of bacterial counts, based on only large pink colonies, on MacConkey agar from the samples investigated in the study

\begin{tabular}{l|ccccc}
\hline \multicolumn{1}{c}{ Sampling areas } & No. of samples & No. of +ve on & \multicolumn{3}{c}{ TVC in MAC (cfu/ml) } \\
\cline { 3 - 6 } collected & 17 & MacConkey agar & Averages & Maximum & Minimum \\
\hline A dairy farm at shikalbaha & 11 & 6 & $2.30 \times 10^{5}$ & $4.00 \times 10^{5}$ & $6.00 \times 10^{4}$ \\
Shikalbaha & 39 & 5 & $7.67 \times 10^{5}$ & $1.10 \times 10^{6}$ & $5.00 \times 10^{5}$ \\
Sholoshahar & 20 & 14 & $2.23 \times 10^{6}$ & $6.00 \times 10^{6}$ & $1.10 \times 10^{4}$ \\
Jalalabad & 19 & 3 & $1.20 \times 10^{7}$ & $1.20 \times 10^{7}$ & $1.20 \times 10^{7}$ \\
City Gate & 22 & 4 & $1.24 \times 10^{6}$ & $1.90 \times 10^{6}$ & $6.00 \times 10^{4}$ \\
Halishahar & 24 & 5 & $1.03 \times 10^{6}$ & $2.10 \times 10^{6}$ & $1.40 \times 10^{5}$ \\
CTG port & 34 & 4 & $1.40 \times 10^{6}$ & $2.70 \times 10^{6}$ & $7.00 \times 10^{5}$ \\
Bataliroad & & 10 & $1.99 \times 10^{6}$ & $9.00 \times 10^{6}$ & $2.30 \times 10^{4}$ \\
Mean & & & & & \\
\hline
\end{tabular}

TVC: Total viable count; MAC: MacConkey agar

Table 4 Antimicrobial susceptibility pattern of E .coli O157 isolates from locally collected raw milk

\begin{tabular}{l|cccc}
\hline \multicolumn{1}{c}{ Antibiotic } & $\begin{array}{c}\text { Concentration } \\
(\mu \mathrm{g})\end{array}$ & $\mathrm{R}-$ No. $(\%)$ & $\mathrm{I}-$ No. $(\%)$ & $\mathrm{S}-$ No. $(\%)$ \\
\cline { 3 - 5 } & 10 & $6(100.0)$ & $0(0.0)$ & $0(0.0)$ \\
Penicillin & 5 & $0(0.0)$ & $2(33.33)$ & $4(66.67)$ \\
Ciprofloxacin & 10 & $0(0.0)$ & $3(50.0)$ & $3(50.0)$ \\
Gentamycin & 10 & $2(33.33)$ & $1(16.67)$ & $3(50.0)$ \\
Streptomycin & 30 & $6(100.0)$ & $0(0.0)$ & $0(0.0)$ \\
Tetracycline & 30 & $4(66.67)$ & $1(16.67)$ & $1(16.67)$ \\
Chloramphenicol & 25 & $5(83.33)$ & $0(0.0)$ & $1(16.67)$ \\
Amoxicillin & 5 & $5(83.33)$ & $1(16.67)$ & $0(0.0)$ \\
Erythromycin & 5 & $4(66.67)$ & $1(16.67)$ & $1(16.67)$ \\
Oxacillin & 25 & $3(50.0)$ & $1(16.67)$ & $2(33.33)$ \\
S/T & & &
\end{tabular}

Table 5 Antimicrobial susceptibility pattern of E.coli non-O157 isolates from locally collected raw milk

\begin{tabular}{l|cccc}
\hline \multicolumn{1}{c}{ Antibiotic } & $\begin{array}{c}\text { Concentration } \\
(\mu \mathrm{g})\end{array}$ & $\mathrm{R}-$ No. $(\%)$ & $\mathrm{S}$ I - No. $(\%)$ & $\mathrm{S}-$ No. $(\%)$ \\
\cline { 2 - 4 } Penicillin & 10 & $7(25.93)$ & $18(66.67)$ & $2(7.41)$ \\
Ciprofloxacin & 5 & $0(0.0)$ & $8(29.63)$ & $19(70.37)$ \\
Gentamycin & 10 & $0(0.0)$ & $12(44.44)$ & $15(55.55)$ \\
Streptomycin & 10 & $7(25.93)$ & $10(37.04)$ & $10(37.04)$ \\
Tetracycline & 30 & $5(18.52)$ & $16(59.26)$ & $6(22.22)$ \\
Chloramphenicol & 30 & $11(40.74)$ & $8(29.63)$ & $8(29.63)$ \\
Amoxicillin & 25 & $4(14.81)$ & $11(40.74)$ & $12(44.44)$ \\
Erythromycin & 5 & $11(40.74)$ & $6(22.22)$ & $10(37.04)$ \\
Oxacillin & 5 & $10(37.04)$ & $7(25.93)$ & $10(37.04)$ \\
S/T & 25 & $6(22.22)$ & $5(18.52)$ & $16(59.26)$ \\
\hline
\end{tabular}




\section{Discussion}

In this study, the extent of contamination of fluid milk marketed in the Chittagong Metropolitan area by E. coli was assessed along with antimicrobial resistance pattern of E.coli positive isolates from the samples. E.coli is an indicator organism to show if any sample/objects is contaminated with materials of faecal origins. E. coli, particularly those belonging to the shiga toxin producing O157 serotype or non-O157 but shiga toxin producing ones themselves are pathogenic. Life threatening disease may be resulted because of consuming milk contaminated with shiga toxin producing $E$. coli belonging to O157:H7 or O157: H- (Tarr et al., 2000; Grant et al., 2011). This is not the only danger; the presence of $E$. coli in milk does indicate that it might also be contaminated with any other enteric pathogens, such as any members of Shigella, Vibrio and others, indicating if such contaminated milk is taken; it can lead to the development of any enteric disease.

The obtained bacterial count results from 186 samples of raw milk are represented in Tables 2 and 3 based on MacConkey agar and blood agar, respectively. The highest and lowest E.coli counts were recorded $1.20 \times 10^{7}$ $\mathrm{cfu} / \mathrm{ml}$ and $1.10 \times 10^{4} \mathrm{cfu} / \mathrm{ml}$, respectively. These results are similar to faecal coliforms $4.2 \times 10^{7} \mathrm{cfu} / \mathrm{ml}$ in raw milk expressed by Fatine Hadrya et al. (2012). The highest total viable count $\left(1.06 \times 10^{9} \mathrm{cfu} / \mathrm{ml}\right)$ and lowest $\left(1.7 \times 10^{6} \mathrm{cfu} / \mathrm{ml}\right)$ in blood agar was recorded in raw sample. Aaku et al. (2004) and Arenas et al. (2004) observed that the total numbers of micro-organisms in pooled raw milk were $5.5 \times 10^{6} \mathrm{cfu} / \mathrm{ml}$ and $10^{6}$ to $10^{7}$ $\mathrm{cfu} / \mathrm{ml}$, respectively and Fatine Hadrya et al. (2012) revealed that the counts of total mesophilic aerobic bacteria was $6.9 \times 10^{8} \mathrm{cfu} / \mathrm{ml}$ in raw milk were randomly collected from six dairies in different locations in Kenitra City (Morocco) from October 2010 to March 2011. In which these values were almost at the same limit of our experiment results.

While examining the fluid milk destined to be marketed at the Chittagong Metropolitan area it can be concluded that a substantial proportion, i.e. one in every five milk samples is seemingly contaminated with $E$. coli here. Milk is usually taken, having boiled in Bangladesh. However, if it is taken raw without any heat-treatment it might pose a serious health-risk to the public health because of its contamination with any enteric pathogens of animal or human origins. Milk is considered as ideal growth media for microorganisms. The total viable count of $E$. coli in any of the positive samples was also very high. It is difficult to assess whether a heavy contamination happened primarily, or having gained enter into a milk sample, the organism multiplied later. The generation time of $E$. coli is 20 minutes (Pierucci and Bacteriol, 1972), suggesting that in every 20 minutes its number becomes double. Therefore, a later proliferation after introduction could be plausible. Wiking et al. (2002) pointed out that the rate of microbial contamination of cow's raw milk is influenced by the health status and hygiene of dairy cows, hygiene of the environment in which dairy cows are housed and milked, methods of udder preparation and milking techniques, methods used for the cleaning and disinfection of milking machines and milk tanks and hygiene of the attendant staff.

The antimicrobial sensitivity tests showed a high level of resistance to most of the antibiotics used. The development of antimicrobial resistance by the bacteria to these drugs poses a major challenge in both human and animal medicine because these drugs are commonly used in the treatment of human patients and in veterinary practice. Uncontrolled usage of antibiotics in treatment of animals and their incorporation in animal feeds has been suspected to account significantly to the increase in antibiotic resistance in human bacterial isolates (WHO, 2000; Galland et al., 2001).

Isolates from the both $E$.coli $\mathrm{O} 157$ and non- $E$.coli O157, penicillin and tetracycline resistance were the highest. This is in agreement with the finding of Olatoye (2010), which recorded a high level of tetracycline resistance of $91.4 \%$ among isolates of E. coli O157:H7. Al Haj et al. (2007) also observed high resistance to tetracycline (81.4\%); Shitandi and Sternesjö (2001) obtained also high resistance to penicillin (72\%) and to tetracycline (57.9\%); O’Brien (1987) also reported high resistance to tetracycline (72\%). The high level of resistance of tetracycline obtained in this study may be as a result of it being the most commonly available antibiotic used as growth promoter and routine chemoprophylaxis among livestock (Olatoye, 2010). This is worrisome considering that tetracycline is a first line drug in Bangladesh, and as in most developing countries, people with gastrointestinal infections readily purchase it across the counter for self-medication (Chigor et al., 2010). Penicillin resistance as obtained from this study may be as a result of the frequent usage of this antibiotic in treating diseases in cattle (Byrne et al., 2003). According to Hart and Kariuki (1998) and Okeke et al. (1995) penicillin and tetracycline are known to be extensively used in developing countries.

S/T $3(50.0 \%)$ for $E$.coli $\mathrm{O} 157$ and 6 (22.22\%) for non- $E$.coli $\mathrm{O} 157$ were obtained in this study really a high rate of resistance. Shroeder et al. (2001) reported that among 189 E. coli O157:H7 isolates recovered from various sources between 1985 and 2000, 19 (10\%) were resistant to this antibiotic. This antimicrobial is commonly used to treat respiratory infections, diarrhoea, mastitis, and other infections in beef and dairy cattle. Resistance was found to be relatively low in streptomycin. This probably may be because of less exposure to the antibiotic due to the discourage use of the antibiotic and the fact that it is usually administered intravenously thereby restricting indiscriminate use (Cheesbrough, 2000). The high prevalence of resistance of E. coli isolates to erythromycin, oxacillin, amoxicillin and chloramphenicol is of importance from the view point of medical and veterinary practice in Bangladesh. This could be a reflection of use and misuse of these antibiotics in the society. This finding is not surprising because outside the hospital environment the general population have easy 
access to various antibiotics at any drug store without any prescription from a medical practitioner.

The development of antimicrobial resistance by the $E$. coli $\mathrm{O} 157: \mathrm{H} 7$ isolates to these drugs poses a major challenge in both human and animal medicine because these drugs are commonly used in the treatment of human patients and in veterinary practice. Uncontrolled usage of antibiotics in treatment of animals and their incorporation in animal feeds has been suspected to account for majority of the increase in antibiotic resistance in human bacterial isolates (WHO, 2000; Galland et al., 2001). The developmental of resistance to antimicrobials occurs through stable genetic change heritable from generation to generation through specific mechanisms including mutation, transduction, transformation, and/or conjugation (Goodman et al., 1990; Metlay et al., 2006). The shedding of the resistant bacteria into the environment by cattle may lead to a widespread dissemination of antibiotic resistant genes to the resident bacteria in the environment (Callaway et al., 2003, 2004; Mashood, et al., 2006).

\section{Conclusion}

$18 \%$ raw milk marketed in Chittagong contains $E$. coli, indicator bacteria for any enteric pathogens. The mean viable count of $E$. coli in the contaminated fluid milk could be $1.88 \times 10^{6} \mathrm{cfu} / \mathrm{ml}$. The antimicrobial susceptibility of $E$. coli isolates showed a high prevalence of resistance to most of the antibiotics used. There is a need to legislate and enforce laws to limit the prescription and dispensing of antibiotics and other drugs to only qualified professionals. Education of the public on the dangers of indiscriminate purchase and use of drugs is also imperative.

\section{Acknowledgements}

The authors are thankful to the Department of Food Processing and Engineering, Faculty of Food Science and Technology, Chittagong Veterinary and Animal Sciences University, Bangladesh and PRTC (Poultry Research and Training Institute) for financial support and necessary facilities for this research.

\section{References}

Aaku EN, Collinson EK, Gashe BA, Mpuchane S. 2004.Microbiological quality of milk from two processingplantsin Gaborone Botswana. Food Control 15:181186.

Aibinu IE, Peters RF, Amisu KO, Adesida SA, Ojo MO, ToluO. 2007. Multidrug Resistance in E. coli O157 Strains and the Public Health Implication. Journal for Animal Science 3(3): 2233.

AlHaj N, MarianaNS, Raha AR, Ishak Z. 2007. Prevalence of Antibiotic Resistance AmongEscherichia coli from Different Sources. Malaysia Research Journal of Pharmacology. 1(2): 4449.

Arenas R, Gonzales L, Bernardo A, Fresno JM, Tornadijo ME.2004. Microbiological and physic chemical changes in Genestoso cheese, a Spanish acid curd variety, throughout ripening. Food Control 15(4):271-279.
Bertu, WJ, Dapar M, Gusi AM, Ngulukun SS, Leo S,Jwander LD. 2010. Prevalence of brucella antibodies in marketed milk in Jos and environs. African Journal of Food Science 4(2): 62 - 64.

Byrne CM, Erol I, Call JE, Kaspar CW, Buege DR, Hiemke CJ, Fedorka-Cray PJ, Benson AK, Wallace FM,Luchansky JB. 2003. Characterization of Escherichia coli O157:H7 from Downer and Healthy Dairy Cattle in the Upper Midwest Region of the United States. Journal of Applied and Environmental Microbiology 69(8): 4683-4688.

Callaway TR, Anderson RC, Edrington TS, Elder RO, Genovese KJ, Bischoff KM, Poole TL, Jung YS, Harvey RB, Nisbet DJ. 2003. Preslaughter intervention strategies to reduce food-borne pathogens in food animals. Journal of Animal Science 81(2):17-23.

Cheesbrough M. 2000. District Laboratory Practice in Tropical Countries.Part 2.United Kingdom: Cambridge University Press, pp 151-220.

Chigor VN, Umoh JV, Smith IS, Igbinosa OE,Okoh IA. 2010. Multidrug Resistance and Plasmid Patterns of Escherichia coli O157 and Other E. coli Isolated from Diarrhoeal Stools and Surface Waters from Some Selected Sources in Zaria, Nigeria. International Journal of Environmental Research and Public Health 7: 3831-3841.

Clinical Laboratory Standards Institute (CLSI). 2005. Clinical Laboratory Standards Institute Performance standards for antimicrobial susceptibility testing, 15th informational supplement, M100-S15 CLSI, Wayne, Chicago, IL, USA.

Donkor ES, Aning KG, Quaye J. 2007.Bacterial contaminations of informally marketed raw milk in Ghana.Ghana Medical Journal 41(2): 58 - 61.

Hadrya F, Elouardi A, Benali D, Hami H,Soulaymani A, Senouci S. 2012. Bacterial quality of informally marketed raw milk in Kenitra city, Morocco. Pakistan Journal of Nutrition 11(8):662669.

Galland CJ, Hyatt RD, Crupper SS,Acheson W.D. 2001. Prevalence, Antibiotic Susceptibility, and Diversity of E. coli O157:H7 Isolates from a Longitudinal Study of Beef Cattle Feedlots. Journal of Applied and Environmental Microbiology67(4):1619-27.

Goodman AG, Theodore WR, Alan SN,Palmer T. 1990. The Pharmacological Basis of Therapeutics: Eighth edition, US: Pergamon Press. pp. 1020- 1021.

Griffin PM, Tauxe RV. 1991. The Epidemiology of Infections Caused by Escherichia coli O157:H7, Other EnterohemorrhagicE. coli, and the Associated Haemolytic Uremic Syndrome. Epidemiologic Reviews 13: 60-98.

Harrigan WF, MacCance ME. 1976. Laboratory Methods in Food and Dairy Microbiology. ${ }^{\text {st }}$ edition, London: Academic Press.

Hart A, Ariuki KS. 1998. Antimicrobial Resistance in Developing Countries. British Medical Journal. 317: 647-650.

Kirby WMM, Bauer AW, Sherries JC, Turck M. 1966. Antibiotics Susceptibility Testing. American Journal of Pathology 45: 493496.

Lei I, Roffey P, Blanchard C,Gu K. 2008. Development of a multiplex PCR method for the detection of six common foodborne pathogens.Journal of Food and Drug Analysis 16(4): $37-43$.

Mashood AR, Minga U, Machugun RK. 2006. Current Epidemiologic Status of EnterohaemorrhagicEscherichia coli 0157:H7 in Africa. Chinese Medical Journal 119(3): 217-22.

Metlay, P.J., Powers, H.J., Dudleys, N.M., Christiansen, K. and Finch, G.R. 2006.Antimicrobial Drug Resistance, Regulation and Research.Emerging Infectious Disease Journal.12: 2.

Molbak K, Mead PS, Griffin PM.2002. Antimicrobial Therapy in Patients with Escherichia coli O157:H7 Infection. Journal of American Medical Association 288:1014-6.

Okeke N, Lamikana A, Edelman R. 1995. Socioeconomic and Behaviourial Factors Leading to Acquired Bacterial Resistance in Developing Countries.Emerging Infectious Diseases5:18-27.

Olatoye IO. 2010. The Incidence and Antibiotics Susceptibility of Escherichia coli O157:H7 from Beef in Ibadan Municipal, Nigeria. African Journal of Biotechnology.9(8): 1196-1199. 
Parekh TS, Subhash R. 2008.Molecular and bacteriological examination of milk from different milch animals with special reference to Coliforms.Current Research in Bacteriology 1(2): 56-63.

Pierucci O. 1972. Chromosome replication and cell division in Escherichia coli at various temperatures of growth. Journal of bacteriology 109(2):848-854.

Schmidt RH, Goodrich RM, Archer DL, Schneider KR. 2003. General overview of the causative agents of foodborne illness.Institute of Food and Agriculture Sciences. University of Florida, USA.

Schroeder CM, Zhao C, DebRoy C, Torcolini J, Zhao S, White GD, Wagner DD, McDermott FP, Walker DR, Meng J. 2002. Antimicrobial Resistance of Escherichia coli O157:H7 Isolated from Humans, Cattle, Swine, and Food. Journal of Applied and Environmental Microbiology 68: 576-581.
Shitandi A, SternesjöA. 2001. Detection of Antimicrobial Residues in Kenyan Milk.Journal of Food Safety 21: 205-215.

WHO. 2000. Global Principles for the Containment of Antimicrobial Resistance in Animals Intended For Food; Report of WHO Consultation With The Participation Of Food and Agriculture Organization of The United Nation and the Office International Des Epizooties, Geneva Switzerland 5- 9 June 2000. Department of Communicable Disease Surveillance and Response.

Wiking L, Larsen LB, Nielsen JH. 2002. Effects of storage conditions on lipolysis, proteolysis and sensory attributes in high quality raw milk. Milchwissenschaft 57:190-194.

Wong CS, Jelacic S, Habeeb RL, Watkins SL,Tarr PI. 2000. The Risk of the Hemolytic-Uremic Syndrome after Antibiotic Treatment of Escherichia coli O157:H7 Infections. New England Journal of Medicine 342:1930-1936. 